\title{
Composição Química e Energética do Milho com Diversos Níveis de Umidade na Colheita e Diferentes Temperaturas de Secagem para Frangos de Corte
}

\author{
Helenice Mazzuco', Irineu Lorini ${ }^{2}$, Paulo Antonio Rabenschlag de Brum ${ }^{3}$, Dirceu Luis Zanotto ${ }^{4}$, \\ Waldomiro Barioni Junior ${ }^{5}$, Valdir Silveira de Avila ${ }^{6,2}$
}

\begin{abstract}
RESUMO - O experimento foi conduzido com o objetivo de avaliar os efeitos dos níveis de umidade na colheita e da temperatura de secagem do milho sobre sua composição química e valores de energia metabolizável aparente corrigida para retenção de nitrogênio (EMAn) para frangos de corte. O milho foi colhido com $35 ; 25 ; 18 ; 15,3$ e $14,3 \%$ de umidade e submetido à secagem a $100^{\circ} \mathrm{C} ; 70^{\circ} \mathrm{C}$ e $40^{\circ} \mathrm{C}$ de temperatura. Os valores de 15,3 e 14,3\% de umidade de colheita do grão não foram submetidos à secagem, sendo o último valor referente ao tratamento que permaneceu na lavoura por 60 dias (milho pós-colheita). A composição química foi determinada segundo AOAC (1995) e a EMAn pelo método de coleta total de excretas, conforme descrito por Hill e Anderson (1958) e fórmulas de Matterson et al. (1965). Quando considerados os valores de EMAn expressos na matéria natural, verificaram-se diferenças significativas entre o milho sem secagem (15,3\% de umidade) e os demais tratamentos. A diferença com o valor mais alto obtido de EMAn, nesse caso, foi de $11,8 \%$ (2864 vs $3247 \mathrm{kcal} / \mathrm{kg}$ ). Isso se deve ao fato de o grão colhido com 15,3\% de umidade ter atingido valores próximos a 24\%, possivelmente devido a um processo de reidratação. Quando considerados os valores de EMAn com base na matéria seca, não houve diferenças entre os tratamentos. O valor nutritivo do milho colhido sob distintos níveis de umidade e submetido à secagem sob diferentes temperaturas permaneceu dentro dos valores padrão tabelados.
\end{abstract}

Palavras-chave: composição química, energia metabolizável aparente corrigida, frangos de corte, milho, secagem, umidade

\section{Chemical and Energy Composition of Corn Harvested with Various Moisture Levels and Different Drying Temperatures to Broiler Chickens}

\begin{abstract}
The experiment was conducted to evaluate the effects of moisture levels at harvest and drying temperatures of corn on its chemical composition and apparent metabolizable energy corrected to zero nitrogen retention (AMEn) to broiler chickens. The corn was harvested with $35 \%, 25 \%, 18 \%, 15.3 \%$ and $14.3 \%$ of moisture and submitted to drying temperatures of 100,70 and $40{ }^{\circ} \mathrm{C}$. The moisture levels of $15.3 \%$ and $14.3 \%$ of corn were not submitted to drying and the last value represented the treatment post-harvesting (60 days after the first harvest). The chemical composition was determined by AOAC (1995) and AMEn assay was carried out by total collection procedure as described by Hill and Anderson (1958) and methodology of Matterson et al. (1965). When the AMEn values were considered on as fed basis, significant differences occured between the treatment of corn no drying and the others. The mean AMEn value was $11.8 \%$ less in energy $(2864 \mathrm{kcal} / \mathrm{kg}$ ) relative to the highest value $(3247 \mathrm{kcal} / \mathrm{kg})$. This is due to grain humidity having reached $24 \%$ on that treatment caused by natural grain natural re-hydration. When the energy values of corn were changed to dry-matter basis, there were no differences among the treatments. There were no major changes in nutritive value of corn harvested with different moisture levels and submitted to various drying temperatures, compared to expected standards, except the AMEn value (as fed basis) when the corn was no drying.
\end{abstract}

Key Words: AMEn, broiler chickens, chemical composition, corn, drying temperatures, moisture

\section{Introdução}

Conforme Rostagno (1993), nas tabelas de composição de alimentos estão descritos os alimentos produzidos em condições normais, entretanto, na prática, sempre existem alimentos com qualidade fora do padrão. No caso dos grãos, a causa poderá ser a infestação de insetos, a proliferação de fungos e, até o processamento inadequado, entre outras. Grãos de má qualidade podem Ter seu valor nutricional comprometido pela alteração da composição química, como consequência da diminuição da biodisponibilidade de alguns nutrientes e/ou proliferação de fungos com ou sem a produção de micotoxinas.

\footnotetext{
1 Zootec., M.Sc., Embrapa Suínos e Aves, Caixa Postal 21, BR 153 Km 110. E.mail: helenice@cnpsa.embrapa.br

2 Eng.-Agr., PhD., Embrapa Trigo, Passo Fundo - RS. E.mail: ilorini@cnpt.embrapa.br

3 Méd. Vet., DSc., Embrapa Suínos e Aves, bolsista do CNPq. E.mail: pbrum@cnpsa.embrapa.br

4 Biólogo, MSc., Embrapa Suínos e Aves. E.mail: zanotto@cnpsa.embrapa.br

5 Estatístico, MSc., Embrapa Suínos e Aves. E.mail: barioni@cnpsa.embrapa.br

6 Eng.-Agr., DSc., Embrapa Suínos e Aves. E.mail: vavila@cnpsa.embrapa.br
} 
Há necessidade do aprimoramento das tabelas de composição de alimentos, pois poderá haver alteração do perfil nutritivo dos ingredientes em função de sua origem, processamento e condições de armazenagem.

Biagi et al. (1996) argumentaram que os grãos deveriam ser colhidos no ponto de maturação fisiológica, quando apresentam teores máximos de amido, proteína, óleo e teor de umidade elevada. No entanto, essa última condição propicia rápida deterioração do produto. Uma colheita mais tardia e com teores de umidade reduzidas nos grãos, favorece a incidência de índices elevados de grãos ardidos, atacados por insetos ou fungos e comprometidos em sua qualidade nutritiva. Conforme os mesmos autores, a secagem é uma operação crítica dentro da sequência de processamento dos grãos, sendo de consenso que a secagem inadequada é a maior causa de deterioração dos grãos nessa série de processos. A secagem é a operação mais importante no beneficiamento de sementes e grãos e tem por objetivo reduzir o teor de umidade a níveis que evitem a colonização fúngica e permitir a conservação segura dos mesmos por um período de tempo relativamente longo (Lazzari, 1999).

Para armazenar sementes e grãos com sucesso ou com um mínimo de perdas qualitativas e quantitativas, é imprescindível a adoção de medidas que previnam o desenvolvimento de fungos e insetos, segundo o último autor. Dentre essas medidas destacam-se: a colheita no momento certo, o manejo de pré-limpeza, secagem e armazenagem. Umidade e temperatura são os principais fatores responsáveis pelo desenvolvimento de fungos, sendo que o primeiro é considerado o mais importante.

A secagem dos grãos de milho para reduzir o teor de umidade abaixo de $13 \%$, tem sido recomendada como um procedimento seguro para a armazenagem, no entanto situações adversas são encontradas no campo.

Muitos fatores podem influir na composição química e no valor energético do milho, como: origem, variedade, processamento, ataque de pragas e doenças, Lopes et al. (1990). Os mesmos autores atentam para a escassez de informação sobre o valor nutritivo do milho quando os grãos estão infestados. A energia metabolizável dos grãos de milho sofre perdas pela ação fúngica (Krabbe, 1995). O milho é um cereal facilmente atacado por pragas que alteram sua composição química e em consequência seu valor nutritivo (Souza et al., 2000). Por exemplo, em condições de campo o carunchamento ocorre concomitantemente a um mau armazenamento, ocorrendo, então, aumento da umidade dos grãos, o que propicia o desenvolvimento de fungos e, consequentemente, a contaminação por micotoxinas. Considerando as informações anteriores, o presente estudo foi proposto com o objetivo de se avaliar a composição química e energética do milho colhido sob diferentes níveis de umidade e submetido à diferentes temperaturas de secagem.

\section{Material e Métodos}

A EMAn foi determinada por meio de estudo desenvolvido com pintos de corte nas unidades experimentais de Metabolismo da Embrapa Suínos e Aves em Concórdia, SC, no período de Junho a Julho de 2000. Para compor os tratamentos, utilizaram-se os níveis de $35 ; 25 ; 18 ; 15,3$ e 14,3\% para umidade na colheita e 100,70 e $40^{\circ} \mathrm{C}$ para as temperaturas de secagem. Para os valores de 15,3 e $14,3 \%$ de umidade de colheita não foi realizada a secagem, sendo o último valor referente ao tratamento que permaneceu no campo por mais de 60 dias após a colheita (milho pós-colheita). Para determinar o momento de colheita do milho na lavoura (exemplo 35\%) de umidade foram coletadas amostras diariamente e levadas ao laboratório para determinar o teor de umidade do grão. Quando o grão atingiu a umidade desejada, foi colhido mecanicamente sendo levado ao secador de leito fixo para secagem a 40,70 e $100^{\circ} \mathrm{C}$. A secagem dos grãos foi monitorada pela determinação da umidade em diversos pontos do secador. Quando chegou a $14 \%$ na média dos pontos de amostragem, o secador foi desligado e o milho foi ensacado e armazenado.

O delineamento experimental foi inteiramente casualizado com 6 repetições de 8 aves/gaiola metabólica (pintos Ross, $50 \%$ de cada sexo).

Foi determinada a composição química do milho com as diferentes porcentagens de umidade na colheita e diferentes temperaturas de secagem, sendo considerado: matéria seca (MS), proteína bruta $(\mathrm{PB})$, fibra bruta $(\mathrm{FB})$, extrato etéreo $(\mathrm{EE})$, cinzas $(\mathrm{Cz})$, cálcio $(\mathrm{Ca})$ e fósforo (P), de acordo com AOAC (1995), e energia bruta (EB), de acordo com Parr Instruments (1984).

Foi utilizado o método de coleta total,conforme Hill e Anderson (1958) para a determinação da EMAn dos milhos que substituíram em $40 \%$, na base da matéria natural, uma ração referência milho/farelo de soja com $21 \%$ de proteína e $3120 \mathrm{kcal} / \mathrm{kg}$ de EMA (Tabela 1). As rações foram fornecidas às aves, à vontade, entre 15 e 23 dias de idade (nove dias), sendo quatro dias de adaptação e cinco de coleta total de 
Tabela 1 - Composição percentual e calculada da ração referência

Table 1 - Percentage and calculated composition of reference diet

\begin{tabular}{lr}
\hline Ingredientes & $(\%)$ \\
Ingredients & \\
\hline Milho (Corn) & 50,89 \\
Farelo de soja (Soybean meal) & 38,72 \\
Óleo de soja (Soybean oil) & 6,49 \\
Fosfato bicálcico (Dicalcium phosphate) & 1,83 \\
Calcário (Limestone) & 0,95 \\
Sal (Salt) & 0,49 \\
DL-Metionina (DL-Methionine) & 0,27 \\
Cloreto de colina (Choline chloride) & 0,11 \\
Premix vitamínico' (Vitaminpremix) & 0,12 \\
Premix mineral2 (Mineralpremix) & 0,05 \\
Anticoccidiano ${ }^{3}$ (Anticoccidial) & 0,05 \\
Promotor ${ }^{4}$ (Growth promoter) & 0,03 \\
Composição calculada & \\
Calculated composition & \\
Proteína bruta (\%) (Crude protein) & 21 \\
Energia metabolizável(kcal/kg) & \\
Metabolizable energy (kcal/kg) & 3120 \\
Metionina (Methionine) & 0,55 \\
Metionina + cistina (Methionine+Cystine) & 0,90 \\
Lisina (Lysine) & 1,22 \\
Cálcio (Calcium) & 0,90 \\
Fósforo disponível (Available phosphorus) & 0,48 \\
\hline Suplementou-seporkgda dieta(Vitaminsuplementcompostion):
\end{tabular}

${ }^{1}$ Suplementou-se por kg da dieta (Vitamin suplement composition): Vit A 10.000 UI; Vit. $D_{3} 2.500$ UI; Vit. E 3,50 mg; Vit. K 3 mg; Vit. $B_{1}$ (tiamin) 2,20 mg; Vit. B2 (riboflavin) $6 \mathrm{mg}$; niacina (niacin) $50 \mathrm{mg}$; ácido pantotênico (Pantothenic acid) $12 \mathrm{mg}$; Vit. $\mathrm{B}_{6} 4 \mathrm{mg}$; ácido fólico (Folic acid) $1 \mathrm{mg}$; biotina (biotin) $0,10 \mathrm{mg}$; Vit. $\mathrm{B}_{12} 20 \mathrm{mcg}$.

2 Suplementou-se por $\mathrm{kg}$ da dieta (Mineral suplement composition): manganês (manganese) $70 \mathrm{mg}$; zinco (zinc) $50 \mathrm{mg}$; ferro (iron) $60 \mathrm{mg}$; cobre (copper) $8 \mathrm{mg}$; iodo (iodine) $0,50 \mathrm{mg}$; selênio (selenium) $0,25 \mathrm{mg}$

${ }^{3}$ Coban $-20 \%$ de monensina sódica (monensin).

${ }^{4}$ Taylan 40.

excretas em intervalos de 24 horas. As excretas coletadas foram individualmente pesadas e armazenadas em freezer. Após o último dia de coleta, as excretas foram descongeladas, reunidas por repetição, homogeneizadas e uma sub amostra $(400 \mathrm{~g})$ foi retirada e enviada ao laboratório para a realização das análises. Foram registradas as quantidades de ração consumida e excreta produzida por unidade experimental, sendo determinados os valores de MS, EB e nitrogênio das rações, das excretas e MS dos alimentos teste (milhos com diferentes teores de umidade e temperaturas de secagem). Os valores de energia metabolizável dos milhos foram obtidos utilizando-se a fórmula de Matterson et al. (1965). Os dados foram submetidos à análise de variância através do Software SAS (1996), aplicando-se análise de contraste e testes múltiplos de média através de SNK (Student Newman-Keuls), com nível de probabilidade a $5 \%$.

\section{Resultados e Discussão}

A composição química e os valores de energia bruta do milho nos distintos tratamentos são mostrados na Tabela 2. Os valores de energia metabolizável aparente corrigida (EMAn) na matéria natural (MN) e na matéria seca (MS) são mostrados na Tabela 3. Para EB, PB e P os valores obtidos ficaram abaixo dos valores mostrados em Embrapa (1991). Para Ca e $\mathrm{Cz}$ os valores foram semelhantes; no caso da FB e do EE os valores obtidos foram superiores.

Os valores obtidos para MS, PB e EE foram superiores aos mostrados por Fischer Jr. et al. (1998) e Nascimento et al. (1998). Os valores de Cz no presente estudo foram bastante inferiores ao obtido pelos últimos autores. Conforme Nascimento et al. (1998), o tipo de processamento pode afetar a composição química dos alimentos nos níveis de $\mathrm{EE}$ e $\mathrm{FB}$ e a última influi diretamente no conteúdo da energia metabolizável.

No estudo de Vyn \& Tollenaar (1998) não se encontrou diferenças nas características químicas dos grãos de milho colhidos com aproximadamente $25 \%$ de umidade, sendo submetidos à secagem a $30^{\circ} \mathrm{C}$ e $60^{\circ} \mathrm{C}$, exceto para o nitrogênio, que teve seu maior valor apresentado no tratamento em que se empregou menor densidade de plantas por metro quadrado. Esses pesquisadores argumentaram que a qualidade do milho varia segundo os híbridos utilizados e que as diferenças de cultivares também influenciam na qualidade nutritiva do grão, devendo ser considerados. Os autores mostraram que a qualidade do grão de milho pode ser afetada pelas condições em que a planta foi cultivada, particularmente com relação à densidade no plantio.

Os resultados de EMAn obtidos nesse trabalho, considerando os valores na MN e MS, ficaram abaixo daqueles apresentados por Rostagno et al. (2000) e Baidoo et al. (1991) respectivamente. Quando considerados os valores de EMAn na matéria natural $(\mathrm{MN})$, diferenças significativas $(\mathrm{P}<0,05)$ ocorreram considerando o Tratamento $10 \mathrm{em}$ que o milho permaneceu sem secagem (15,3\% de umidade), evidenciando-se o menor valor em EMAn quando comparado aos demais tratamentos. O valor médio de EMAn nesse caso foi $11,8 \%$ menor que o valor mais alto obtido (2864 vs $3247 \mathrm{kcal} / \mathrm{kg}$ ). Isso se deve ao fato da umidade do grão do Tratamento 10 atingir valores próximos à $24 \%$, possivelmente devido a um processo de reidratação ocasionado pela queima da MS em função da respiração natural do grão durante o período de armazenamento.

No entanto, quando os valores foram transforma- 
dos com base na matéria seca não foi detectada diferença significativa $(\mathrm{P}>0,05)$, embora em valores absolutos o Tratamento 10, sem secagem, apresentou menos $95 \mathrm{kcal} / \mathrm{kg}$ quando comparado ao Tratamento 9 em que se aplicou $40^{\circ} \mathrm{C}$ na secagem dos grãos colhidos com $18 \%$ de umidade. Leeson et al. (1993) sugeriram reduzir os valores de energia metabolizável do milho em, aproximadamente, 12 $\mathrm{kcal} / \mathrm{kg}$ para cada $1 \%$ de aumento no teor de umidade do grão, considerando como valor base na colheita $30 \%$ de umidade. No presente estudo entretanto, essa relação não foi evidenciada.

Aplicando-se os contrastes de interesse entre tratamentos não se detectaram diferenças significativas.

Tabela 2 - Valores de composição proximal ${ }^{1}(\%)$ e de energia bruta $(\mathrm{kcal} / \mathrm{kg})$ do milho submetido à diferentes níveis de umidade na colheita e de temperaturas de secagem

Table 2 - Chemical composition (\%) and crude energy $(\mathrm{kcal} / \mathrm{kg})$ of corn submitted to different moisture levels at harvest and drying temperatures

\begin{tabular}{|c|c|c|c|c|c|c|c|c|}
\hline $\begin{array}{l}\text { Tratamentos } \\
\text { Treatments }\end{array}$ & $\begin{array}{l}\text { MS } \\
D M\end{array}$ & $\begin{array}{l}\mathrm{PB} \\
C P\end{array}$ & $\begin{array}{l}\mathrm{FB} \\
\mathrm{CF}\end{array}$ & $\begin{array}{l}\mathrm{EE} \\
E E\end{array}$ & $\begin{array}{l}\mathrm{Cz} \\
A s h\end{array}$ & $\begin{array}{c}\mathrm{Ca} \\
\text { Calcium }\end{array}$ & $\begin{array}{c}\mathrm{P} \\
\text { Phosphorus }\end{array}$ & $\begin{array}{c}\mathrm{EB} \\
\text { Crude energy }\end{array}$ \\
\hline T1 (35/100) & 85,29 & 8,22 & 2,77 & 4,06 & 1,15 & 0,033 & 0,23 & 3794 \\
\hline T2(35/70) & 85,73 & 7,78 & 2,54 & 4,24 & 1,14 & 0,037 & 0,23 & 3799 \\
\hline T3 (35/40) & 86,14 & 7,62 & 2,12 & 4,40 & 1,15 & 0,038 & 0,22 & 3814 \\
\hline $\mathrm{T} 4(25 / 100)$ & 86,08 & 7,75 & 2,36 & 4,12 & 1,23 & 0,036 & 0,24 & 3823 \\
\hline T5(25/70) & 85,75 & 7,89 & 1,96 & 4,24 & 1,20 & 0,036 & 0,25 & 3800 \\
\hline T6 (25/40) & 83,89 & 7,59 & 2,33 & 4,05 & 1,09 & 0,038 & 0,23 & 3723 \\
\hline T7 (18/100) & 86,77 & 7,04 & 2,32 & 4,70 & 1,00 & 0,043 & 0,20 & 3838 \\
\hline $\mathrm{T} 8(18 / 70)$ & 85,04 & 7,19 & 2,39 & 4,34 & 1,03 & 0,022 & 0,21 & 3787 \\
\hline Т9 $(18 / 40)$ & 83,28 & 7,21 & 2,48 & 4,38 & 0,97 & 0,019 & 0,23 & 3690 \\
\hline $\begin{array}{l}\text { T10 (sem secagem) } \\
\text { No drying }\end{array}$ & 76,09 & 6,78 & 3,23 & 4,23 & 0,94 & 0,017 & 0,19 & 3379 \\
\hline $\begin{array}{l}\text { T11(Pós-colheita) } \\
\text { Post-harvesting }\end{array}$ & 84,81 & 7,15 & 2,99 & 4,26 & 0,95 & 0,047 & 0,20 & 3757 \\
\hline
\end{tabular}

${ }_{1}^{1} \mathrm{MS}(D M)=$ matéria seca $($ Dry matter $) ; \mathrm{PB}(C P)=$ proteína bruta (crude protein); $\mathrm{FB}(C F)=$ fibra bruta $($ Crude fiber);EE = extrato etéreo $($ Ether extract).

${ }^{2}$ Milho com níveis de umidade de colheita (\%) e submetido à secagem sob diferentes temperaturas ( $\left.{ }^{\circ} \mathrm{C}\right)$ (Corn with different moisture levels [\%] at harvest and drying temperatures $\left.\left[{ }^{\circ} \mathrm{C}\right]\right)$.

Tabela 3 - Valores de energia metabolizável aparente corrigida (EMAn) na matéria natural (MN) e na matéria seca (MS) do milho submetido a diferentes tratamentos

Table 3 - AMEn values as fed basis and dry matter basis of corn submitted to different treatments

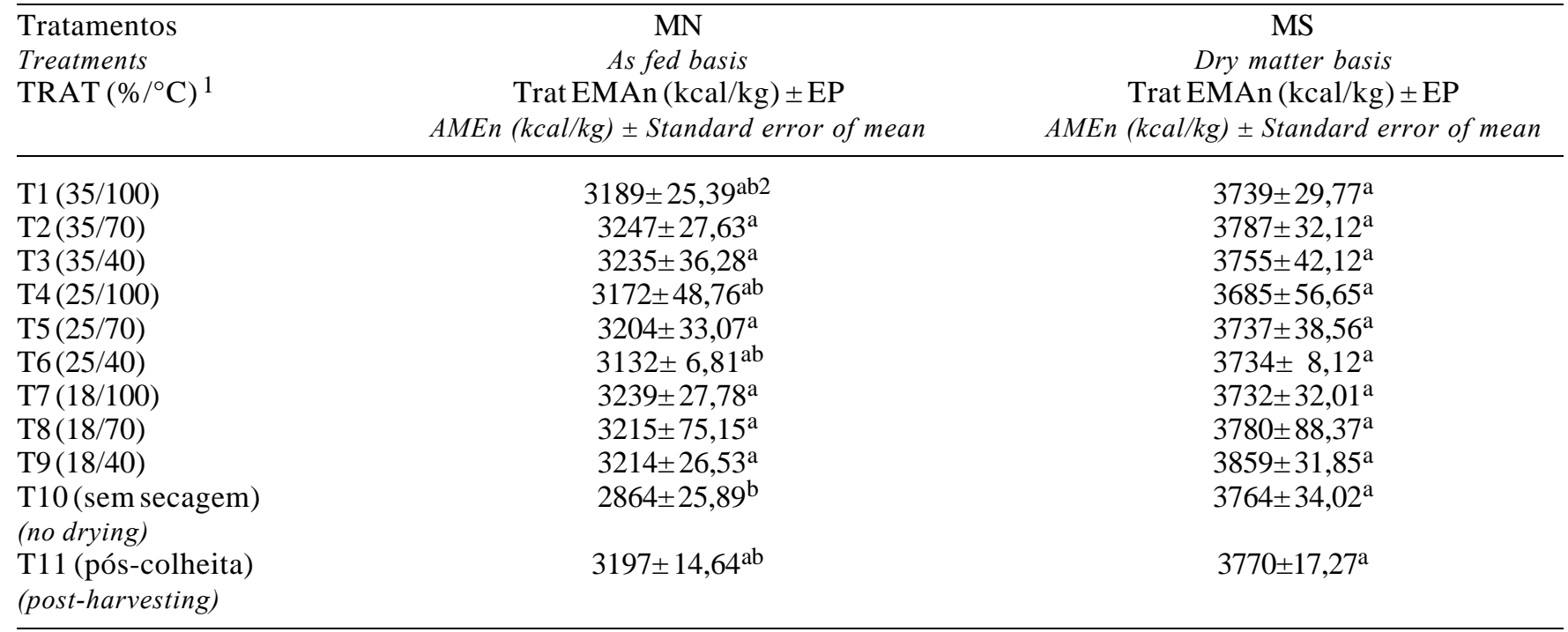

\footnotetext{
${ }^{1}(\%)=$ Umidade na colheita em porcentagem; $\left({ }^{\circ} \mathrm{C}\right)=$ temperaturas de secagem do grão em ${ }^{\circ} \mathrm{C}$ dos tratamentos $\left(\%=\right.$ moisture level; ${ }^{\circ} \mathrm{C}=$ drying temperatures).

2 Médias na coluna com letras distintas, diferença significativa (Teste $\mathrm{T} ; \mathrm{P}<0,05)$.

${ }^{2}$ Means within a column with different superscript are significantly different (Test $\left.T ; P<.05\right)$.
} 


\section{Conclusões}

O valor nutritivo do milho colhido sob distintos níveis de umidade e submetido à secagem sob diferentes temperaturas permaneceu dentro dos valores padrão tabelados.

As condições de colheita e secagem dos grãos não influenciaram a composição química e o valor energético do milho com base na MS para frangos de corte.

\section{Literatura Citada}

ASSOCIATION OF OFFICIAL ANALYTICAL CHEMISTS AOAC. Official methods of analysis. 16.ed. Washington, D.C.: 1995 .

BAIDOO, S.K.; SHIRES, A.; ROBBLER, A.R. Effect of kernel density on the apparent and true metabolizable energy value of corn for chickens. Poultry Science, v.70, n.10, p.21022107, 1991.

BIAGI, J.D.; SILVA, L.O.N.; MARTINS, R.R. Importância da qualidade dos grãos na alimentação animal. In: SIMPÓSIO LATINO AMERICANO DE NUTRIÇÃO ANIMAL E SEMINÁRIO SOBRE TECNOLOGIA DA PRODUÇÃO DE RAÇÕES, 1996, Campinas. Anais... Campinas: Colégio Brasileiro de Nutrição Animal, 1996. p.21-45.

EMPRESA BRASILEIRA DE PESQUISA E AGROPECUÁRIA - EMBRAPA. Tabela de composição química e valores energéticos de alimentos para suínos e aves. 3.ed. Concórdia: CNPSA, 1991. 97p. (Documentos, 19).

FISCHER JR., A.A.; ALBINO, L.F.T.; ROSTAGNO, H.S. et al. Determinação dos valores de energia metabolizável de alguns alimentos usados na alimentação de aves. Revista Brasileira de Zootecnia, v.27, n.2, p.314-318, 1998.

HILL, F.W.; ANDERSON, D.L. Comparison of metabolizable energy and productive energy determination with growing chicks. Journal of Nutrition, v.64, p.587-603, 1958.

KRABBE, E.L. Efeito do desenvolvimento fúngico em grãos de milho durante o armazenamento e do uso do ácido propiônico sobre as características nutricionais e o desempenho de frangos de corte. Porto Alegre: Universidade Federal do Rio Grande do Sul, 1995. 176p. Dissertação (Mestrado em Zootecnia) - Universidade Federal do Rio Grande do Sul, 1995.

LAZZARI, F.A. Controle de micotoxinas no armazenamento de grãos e subprodutos. In: SIMPÓSIO SOBRE MICOTOXINAS EM GRÃOS. Fundação Cargill, 1999. Santo Amaro. Anais... Santo Amaro: Fundação ABC, 1999. p.81-106.
LEESON, S.; YERSIN, A.; VOLKER, L. Nutritive value of the 1992 corn crop. Journal of Applied Poultry Research, v.2, n.3, p.208-213, 1993.

LOPES, D.C.; DONZELLE, J.L.; ALVARENGA, J.C. et al. Efeito do nível de carunchamento do milho sobre a disgestibilidade de sua proteína e energia para suínos em crescimento. Revista da Sociedade Brasileira de Zootecnia, v.19, n.3, p.181-185, 1990.

MATTERSON, L.D.; POTTER, L.M.; STUTZ, M.W. The metabolizable energy of feed ingredients for chickens. Agricultural Experimental Station Research Report, v.7, p.3-11, 1965 .

NASCIMENTO, A.H.; GOMES, P.C.; ALBINO, L.F.T. et al. Valores de composição química e energética de alimentos para frangos de corte. Revista Brasileira de Zootecnia, v.27, n.3, p.579-583, 1998.

PARR INSTRUMENTS CO. Instructions for the 1241 and 1242 adiabatic calorimeters. Moline, 1984. 29p. (Parr Manual,153).

ROSTAGNO, H.S. Disponibilidade de nutrientes em grãos de má qualidade. In: Conferência Apinco de Ciência e Tecnologia Avícolas, Santos - SP, 1993, FACTA, Campinas, p.129-139, 1993.

ROSTAGNO, H.S.; ALBINO, L.F.T.; DONZELE, J.L. et al. Tabelas Brasileiras para aves e suínos; composição de alimentos e exigências nutricionais. Viçosa, MG: Universidade Federal de Viçosa, 2000. 141p.

SAS INSTITUTE. System for Microsoft Windows, Release 6.12, Cary: 1996. (CD ROM)

SOUZA, A.V.C.; SANTOS, J.P.; LOPES, D.C. et al. Detecção de micotoxinas em milhos em diferentes níveis de carunchamento. In: REUNIÃO ANUAL DA SOCIEDADE BRASILEIRA DE ZOOTECNIA, 37., 2000, Viçosa, MG. Anais...Viçosa: Sociedade Brasileira de Zootecnia, 2000. p.268.

VYN, T.J.; TOLLENAAR, M. Changes in chemical and physical quality parameters of maize grain during three decades of yield improvement. Field Crops Research, v.59, p.135140, 1998. 